\title{
An addition of two Tortricidae species to the Bulgarian fauna with notes on genital morphology (Lepidoptera)
}

\author{
Boyan Zlatkov ${ }^{1}$, Ognyan Sivilov ${ }^{2}$
}

(1) Institute of Biodiversity and Ecosystem Research, Bulgarian Academy of Sciences, 1 Tsar Osvoboditel Blvd, 1000 Sofia, Bulgaria, bzlatkov@gmail.com; https://orcid.org/0000-0002-5704-1634

(2) Department of Zoology and Anthropology, Faculty of Biology, Sofia University St Kliment Ohridski, 8 Dragan Tsankov Blvd, 1164 Sofia, Bulgaria, osivilov@gmail.com; https://orcid.org/0000-0003-3497-8237

\begin{abstract}
Two species, Falseuncaria degreyana and Epibactra immundana, are reported new for Bulgaria. They were found in endangered grassland habitats in the Danubian Plain. The moths and their genitalia are illustrated, and the vesicae are described for the first time.
\end{abstract}

Keywords: endophallus, faunistics, steppes, vesica

\section{Introduction}

Two field expeditions in the autumn of 2020 in the Danubian Plain were a part of a larger scale study of endangered grassland habitats in the country. Several species interesting from faunistical point of view were registered. Among them, two species of the family Tortricidae, Falseuncaria degreyana (McLachlan, 1869) and Epibactra immundana (Eversmann, 1844), appeared new for Bulgaria. The latter is of particular interest, it has been found in relatively few localities in steppe areas of Europe and Asia. The first species is widely distributed in various habitats in Europe, but never recorded in Bulgaria, which may due to overlooking. In this paper we provide faunistical information for the two species and also describe the unknown morphology of the vesica (endophallus), which demonstrates some peculiar characters.

\section{Methods}

The moths were collected at night by attraction to lamps with rich ultraviolet spectrum, killed with eth- $\mathrm{yl}$ acetate, pinned and set in the field. The genitalia were dissected generally following Robinson (1976). The vesicae were prepared and drawn according to Zlatkov (2011) and Zlatkov and Huemer (2017). For descriptions of certain structures, terminology from Anzaldo et al. (2014) and Génier (2019) was adopted. The specimens were preserved in the collection of the Institute of Biodiversity and Ecosystem Research, Sofia, Bulgaria.

\section{Results and discussion}

Falseuncaria degreyana (McLachlan, 1869)

Material: $1 \mathrm{\delta}$, Vidin District, Archar, N 43.8026, E $22.9322^{\circ}$, $100 \mathrm{~m}$ a.s.1., 12.ix.2020, leg. B. Zlatkov; 1 $\widehat{\sigma}$, the same but $\mathrm{N} 43.80287^{\circ}, \mathrm{E} 22.9475^{\circ}, 80 \mathrm{~m}$ a.s.1., 12.x.2020, leg. B. Zlatkov and O. Sivilov; 1 đ̃, Lom District, Orsoya, N 43.7778 ${ }^{\circ}$, E 23.0622 ${ }^{\circ}, 30 \mathrm{~m}$ a.s.1., 13.ix.2020, leg. B. Zlatkov.

Faunistical notes: New species for Bulgaria. Falseuncaria degreyana is widely distributed in Europe and is also known from Kazakhstan, Tajikistan, Kyr- 
Boyan Zlatkov, Ognyan Sivilov
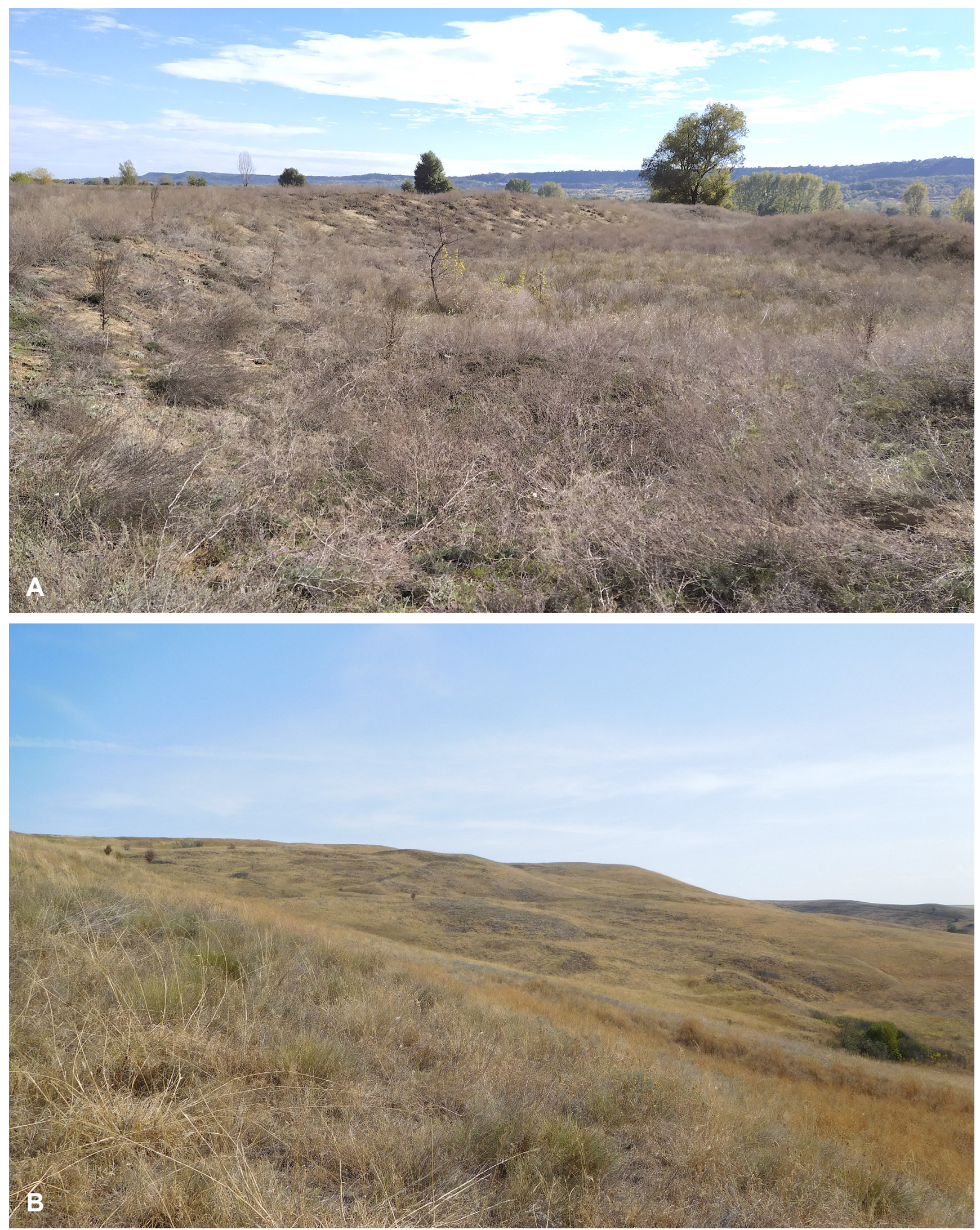

Fig. 1. Endangered habitats in northern Bulgaria - (A) Pannonic inland dunes near Orsoya, (B) Pannonic loess steppe near Hadzhidimitrovo (courtesy by D. Chobanov). 
A
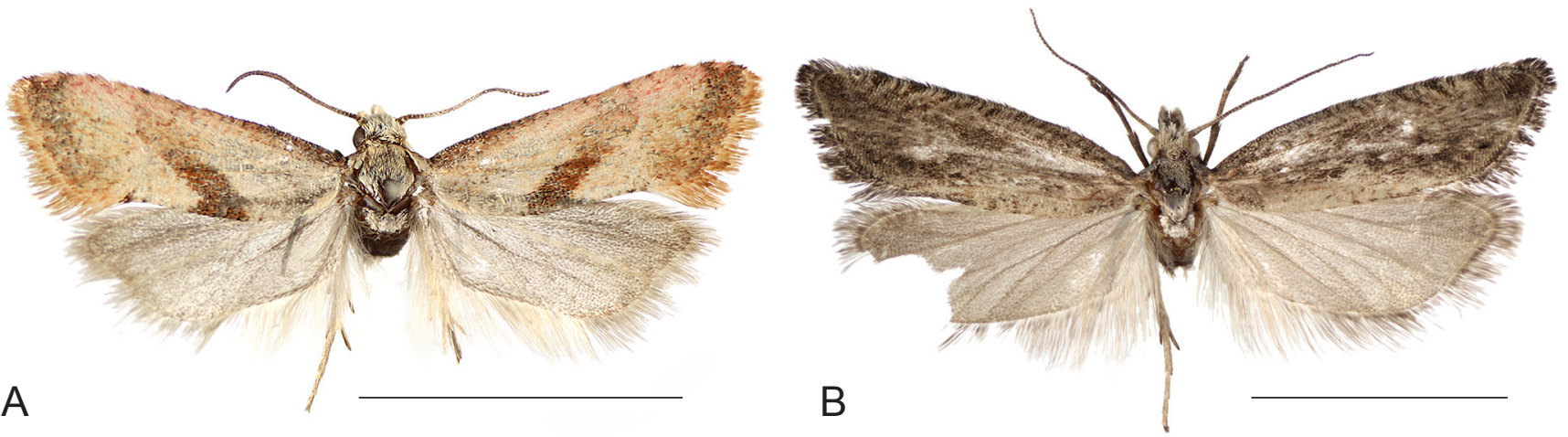

Fig. 2. Tortricidae species new for Bulgaria - (A) Falseuncaria degreyana, (B) Epibactra immundana. Scale bar 5 mm.
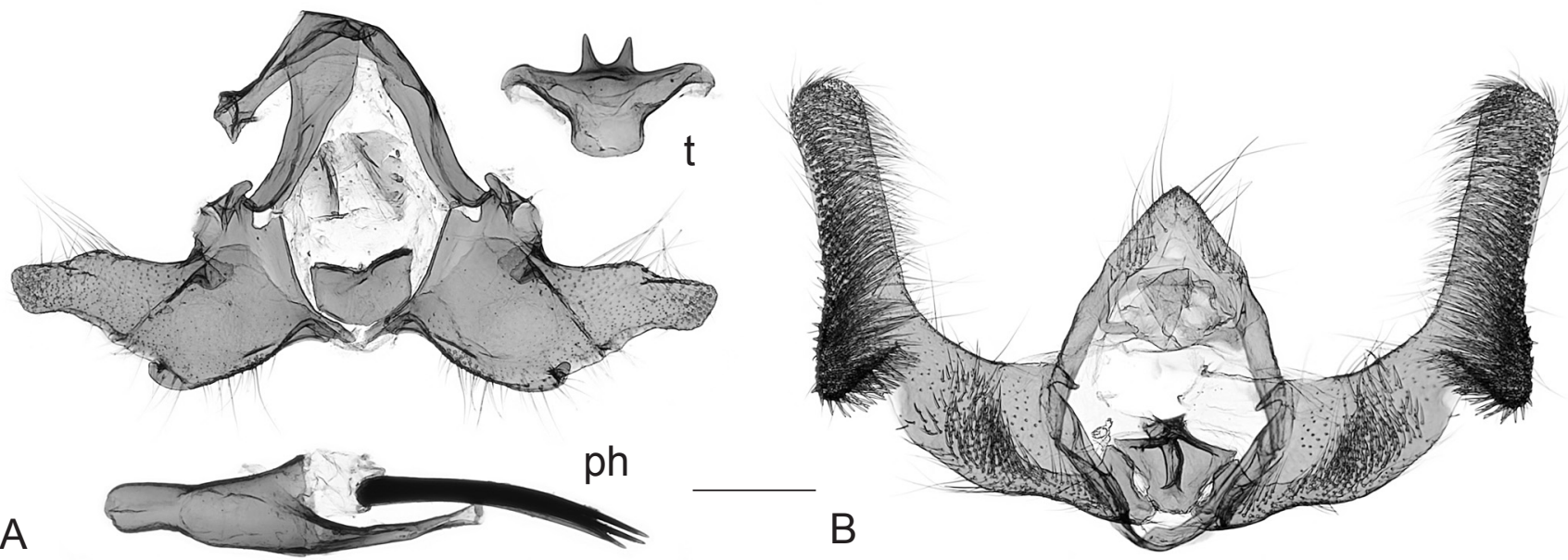

Fig. 3. Male genitalia - (A) Falseuncaria degreyana, transtilla (t) dissected out, phallus (ph) shown in dorsal view; (B) Epibactra immundana, phallus dissected out and illustrated on figure 4. Scale bar $250 \mu \mathrm{m}$, all to scale.

gyzstan and western Mongolia (Razowski, 2009). The Bulgarian records come from the northern part of the country, near the Danube. The locality near Archar is a Pannonic sand steppe, and that of Orsoya (Fig. 1A) belongs to the Pannonic inland dunes. Both are critically endangered habitats in Bulgaria according to Tzonev (2015b), Tzonev and Gussev (2015). The species is externally similar to Cochylis roseana (Haworth, [1811]) and Falseuncaria ruficiliana (Haworth, [1811]) and may have been overlooked by former authors studied the fauna of the country giving an impression for rarity.

Morphological notes: The background of the forewings is creamy, with pink or red suffusion in costal and terminal parts, markings brownish red (Fig. 2A). The genitalia of the species (Fig. 3A) are very distinctive and well documented (e.g. Razowski 2002), but the morphology of the vesica is not described until now.

Phallus wide, mostly membranous dorsally, with long caudal semicylindrical process emerging ventrally at left side and bearing group of small spines (acanthae). Vesica (Fig. 4A, B) relatively small consisting of larger ovoid main part at right apically bearing bundle of seven large non-deciduous cornuti, and thin cylindrical part at left bearing gonopore and long cylindrical diverticulum with small non-deciduous cornuti. Large cornuti aciculate, capitate, basally attached, stout and robust, slightly bent. Small cornuti denticulate, non-capitate (acanthae), longer in apical part of diverticulum.

Similarly to other studied Cochylini (Zlatkov, 2011), the vesica of $F$. degreyana is relatively complex, with lateral gonopore and non-deciduous cornuti. The 


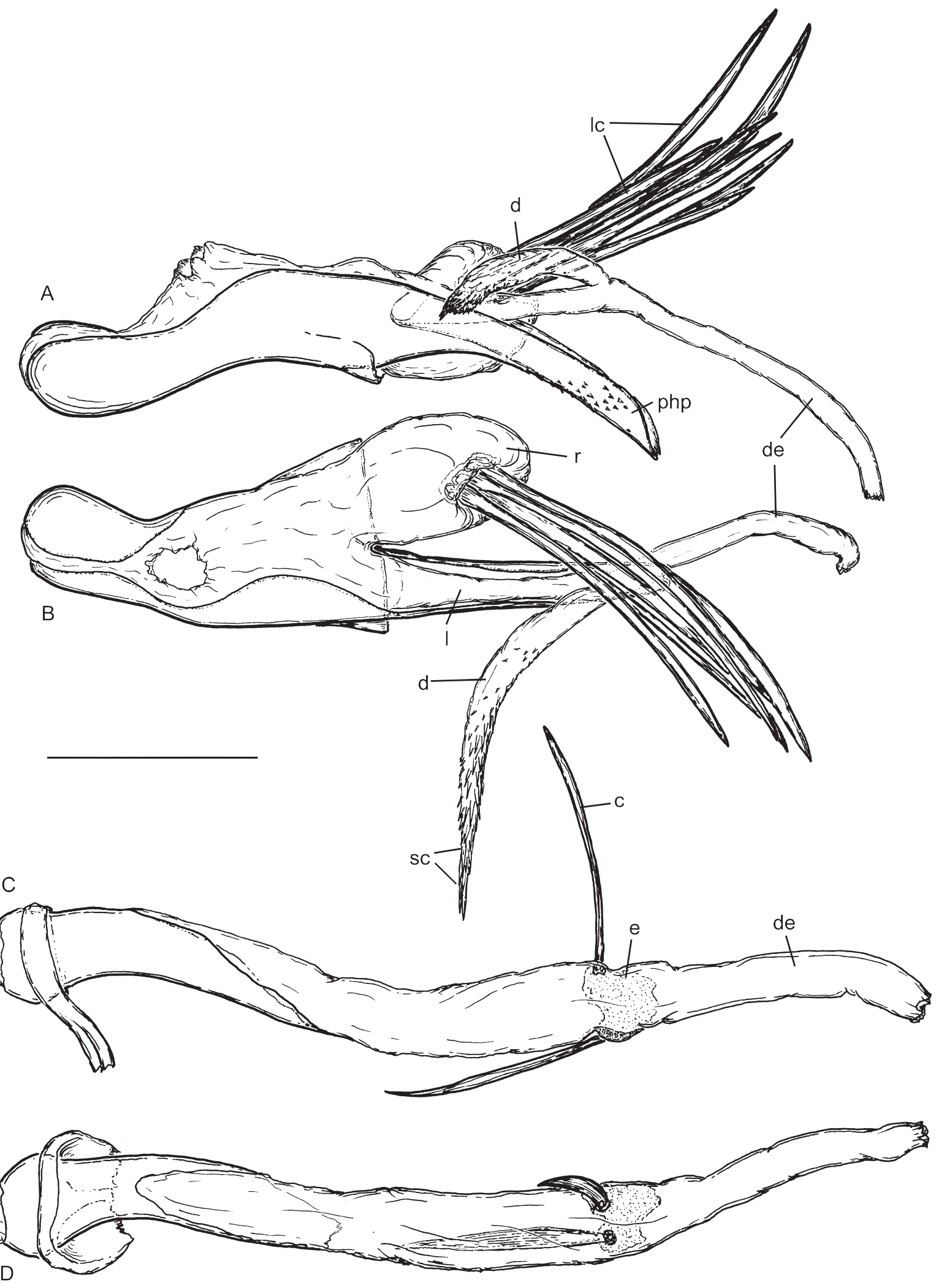

Fig. 4. Phallus with everted vesica (endophallus) of Falseuncaria degreyana (A, B) and Epibactra immundana (C, D) - (A, C) left view; (B, D) dorsal view; (c) cornutus, (d) diverticulum, (de) ductus ejaculatorius, (e) endophallite, (1) left part of vesica, (lc) large cornuti, (php) ventral phallic process, (r) right part of vesica, (sc) small cornuti. Scale bar $250 \mu \mathrm{m}$, all to scale. 
long, thin diverticulum at the left side is not known in any other species of the tribe (unpublished observations). In functional condition (with inverted ductus ejaculatorius), this diverticulum is most probably pointed caudad, laying in the semicylindrical ventral process of the phallus, with gonopore near the middle of the process. Perhaps the diverticulum and the phallic process are a functional entity during copulation. In any case the significance of these structures deserves further scrutiny from functional point of view.

\section{Epibactra immundana (Eversmann, 1844)}

Material: 3 $\widehat{\partial}$, Svishtov District, Hadzhidimitrovo, $\mathrm{N} 43.5364^{\circ}$, E $25.4834^{\circ}, 80 \mathrm{~m}$ a.s.1., 14.x.2020, leg. B. Zlatkov and O. Sivilov.

Faunistical notes: New species for Bulgaria. Epibactra immundana is a locally distributed species recorded from Austria, Czech Republic, Slovakia, Hungary, Ukraine, Romania, Volgo-Ural region of Russia, Transcaucasia, Kazakhstan, Southern Siberia (western, central and eastern parts) (Kasy, 1958; Kuznetsov \& Jalava, 1988; Anikin et al., 2006; Šumpich \& Skyva, 2008; Aarvik, 2013; Bidzilya et al., 2013). According to the sources, the species is connected with steppe habitats of Eurasia. Its habitat in Bulgaria belongs to the Pannonic loess steppe grasslands, which occur in the country only in the northern part of the Danubian Plain and are classified as endangered habitats (Tzonev, 2015a) (Fig. 1B).

Morphological notes: The species is characterised by elongated and relatively narrow, pointed forewings with costal fold, predominantly grey-brownish background and weakly expressed markings. The collected specimens are relatively worn (Fig. 2B). The shape of genitalia resembles other allied genera of the tribe Eucosmini (Fig. 3B) and are described in detail e. g. by Razowski (2003). The everted vesica is described here for the first time (Fig. 4C, D):

Phallus tubular, with syringe needle caudal end and slightly widened coecum. Vesica tubular, straight, as long as phallic tube, with wide gonopore and two non-deciduous similarly shaped cornuti (ventral and dorsal) attached apically. Cornuti aciculate, capitate, basally attached, robust, flattened in adaxial-abaxial direction, slightly bent, with weak longitudinal grooves. Transitional area between ductus ejaculatorius and vesica with ventrolateral endophallite on the right side.
The general shape of the vesica is typical for Eucosmini (Zlatkov, 2016), and similarly to many other genera bears an endophallite (though not so well developed as in Pelochrista Lederer, 1859, Eucosma Hübner, 1823, Epiblema Hübner, 1825 and Notocelia Hübner, 1825). A unique character among the other genera of the tribe is the presence of two very large non-deciduous cornuti attached apically on the vesica. This condition reminds Notocelia but the cornuti in the latter are cylindrical, shorter and are combined with a bundle of deciduous cornuti. The position of the gonopore cannot be determined precisely from macerated structures, presumably it is in the area located basally to the cornuti sockets.

\section{Acknowledgements}

This study is supported by the National Science Fund of the Republic of Bulgaria, grant No. KP-06-N31/13 from 11.12.2019, to which we express our gratitude. We thank also D. Chobanov (Sofia, Bulgaria) who provided a photograph of the habitat of E. immundana.

\section{References}

Aarvik L.E. 2013 Fauna Europaea: Tortricidae. In: Karsholt O., Nieukerken, E.J. van 2013 Fauna Europaea: Lepidoptera, Moths. Fauna Europaea version 2017.06, https://fauna-eu.org

Anikin V., Sachkov S., Zolotuhin V., Nedoshivina S., Trofimova T. 2006 "Fauna Lepidopterologica Volgo-Uralensis" 150 years later: Changes and additions. Part 9. Tortricidae. Atalanta 37 (3/4): 409-445.

Anzaldo S.S., Dombroskie J., Brown J.W. 2014 Morphological variation, taxonomic distribution, and phylogenetic significance of cornuti in Tortricinae (Lepidoptera: Tortricidae). Proceedings of the Entomological Society of Washington 116 (1): 1-31. https://doi.org/10.4289/0013-8797.116.1.1

Bidzilya A.V., Budashkin Yu.I., Goloborod'ko K.K., Demyanenko S.A., Zhakov A.V. 2013 New and interesting records of Microlepidoptera (Lepidoptera) from Ukraine. Contribution 2. Eversmannia 33: 23-30. (In Russian)

Génier F. 2019 Endophallites: a proposed neologism for naming the sclerotized elements of the insect 
endophallus (Arthropoda: Insecta). Annales de la Société entomologique de France (N.S.). https:// doi.org/10.1080/00379271.2019.1685907

Kasy F. 1958 Epibactra sareptana HS. neu für Niederösterreich und Österreich (Lep., Tortr.). Zeitschrift der Wiener Entomologischen Gesellschaft 43 (6): 6-7.

Kuznetsov V.I., Jalava J. 1988 Soviet-Finnish entomological expeditions to Southern Siberia 19821984. 2. Tortricidae (Lepidoptera). Nota lepidopterologica 11 (2): 126-138.

Razowski J. 2002 Tortricidae (Lepidoptera) of Europe. Volume 1. Tortricinae and Chlidanotinae. Slamka, Bratislava, $247 \mathrm{pp}$.

Razowski J. 2003 Tortricidae (Lepidoptera) of Europe. Volume 2. Olethreutinae. Slamka, Bratislava, $301 \mathrm{pp}$.

Razowski J. 2009 Tortricidae of the Palaearctic Region. Volume 2. Cochylini. Slamka, Bratislava, $195 \mathrm{pp}$.

Robinson G. 1976 The preparation of slides of Lepidoptera genitalia with special reference to the Microlepidoptera. Entomologist's Gazette 27:127132.

Šumpich J., Skyva J. 2008 Faunistic records from the Czech Republic - 255. Klapalekiana 44: 83-85.
Tzonev R. 2015a 07E1 Danubian loess steppes. In: Biserkov V. et al. (eds) Red Data Book of the Republic of Bulgaria. Volume 3. Natural habitats. BAS \& MoEW, Sofia, 145-147.

Tzonev R. 2015b 13E1 Danubian sand dunes and inland dunes (gredove) from sandy loess. In: Biserkov V. et al. (eds) Red Data Book of the Republic of Bulgaria. Volume 3. Natural habitats. BAS \& MoEW, Sofia, 161-162.

Tzonev R., Gussev C. 2015 09E1 Danubian sand steppes. In: Biserkov V. et al. (eds) Red Data Book of the Republic of Bulgaria. Volume 3. Natural habitats. BAS \& MoEW, Sofia, 151-152.

Zlatkov B. 2011 A preliminary study of everted vesicae of several leafrollers (Tortricidae). Nota lepidopterologica 33 (2): 285-300.

Zlatkov B. 2016 On the vesica of Eucosmini and Grapholitini (Insecta: Lepidoptera: Tortricidae). Zootaxa 4168(2): 297-312. https://doi.org/10.11646/ zootaxa.4168.2.4

Zlatkov B., Huemer P. 2017 Allopatric cryptic diversity in the alpine species complex Phtheochroa frigidana $\mathrm{s}$. lat. (Lepidoptera: Tortricidae). European Journal of Taxonomy 368: 1-25. https://doi. org/10.5852/ejt.2017.368 